
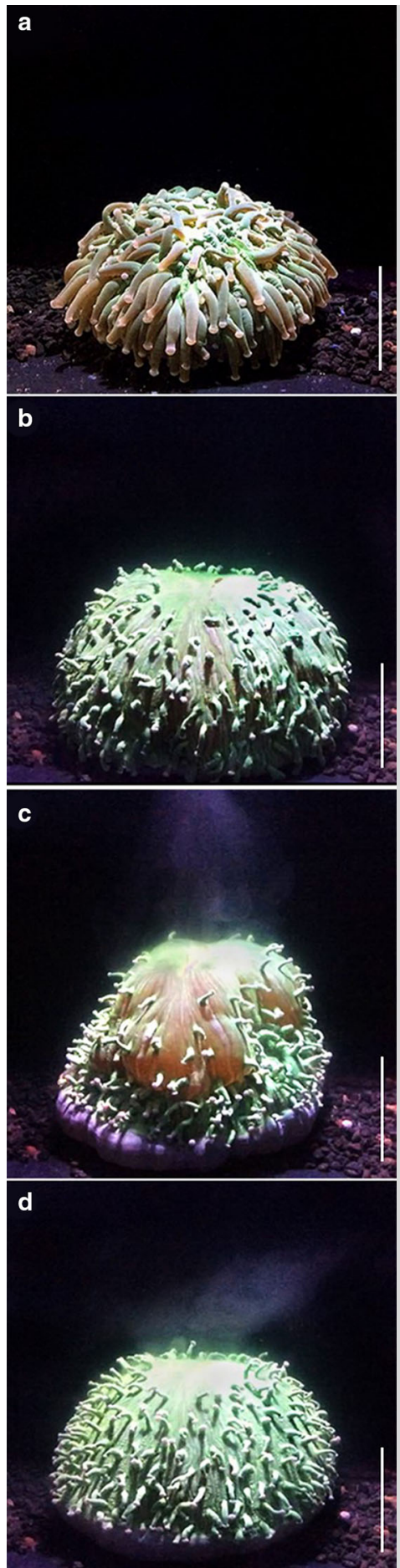

Fig. 1 Temporal sequence of pulsed inflation by Heliofungia actiniformis to remove Symbiodinium. a Acclimated coral at $26^{\circ} \mathrm{C}$. b Inflation maximum before contraction. c Contraction and expulsion of zooxanthellae. d Even after expulsion the corals often maintain a level of inflation. Scale bar $5 \mathrm{~cm}$

\section{Expulsion of Symbiodinium by pulsed inflation under hyperthermal stress in Heliofungia actiniformis}

The biological or physical mechanisms that cause differences in the susceptibility of corals to thermal stress are not well defined (Wooldridge 2014). Understanding coral responses to thermal stress and tolerance mechanisms is important for predicting how corals will fare with elevated ocean temperatures. Using time-lapse photography, we observed the scleractinian coral Heliofungia actiniformis employ pulsed inflation to expel symbionts while under thermal stress.

Heliofungia actiniformis specimens were exposed to elevated water temperatures in a $10-\mathrm{L}$ aquarium system for up to $8 \mathrm{~d}$ to encourage bleaching. An image was collected every $3 \mathrm{~s}$. Temperatures were raised from 26 to $32{ }^{\circ} \mathrm{C}$ in the first $12 \mathrm{~h}$ and maintained at $32{ }^{\circ} \mathrm{C}\left( \pm 0.5^{\circ} \mathrm{C}\right)$ for the duration of the experiment. Within the first $2 \mathrm{~h}$ of exposure, $H$. actiniformis began expelling Symbiodinium from the tissue. A green plume of symbiont cells was expelled via the mouth during tissue inflation and contraction (Electronic Supplementary Material, ESM, Video S1). The intensity and magnitude of the pulses increased over a 55-h period, with coral tissue expanding up to $340 \%$ of its original state (Fig. 1b). Corals survived between 2 and $8 \mathrm{~d}$ under elevated temperature conditions. There was some degradation of the epidermal tissue during the later stages of the experiments.

Pulsed inflation has been observed during other types of environmental stress including burial by sediment (Bongaerts et al. 2012). It also appears to be a physiological response to thermal stress which facilitates the rapid expulsion of Symbiodinium, increasing the chance of non-lethal bleaching. A high level of resilience to thermal stress has been described in H. actiniformis (Hoeksema 1991).

Acknowledgments The project was funded by Australian Research Council Discovery Project DP1096184 to L.D. Nothdurft.

\section{References}

Bongaerts P, Hoeksema BW, Hay KB, Hoegh-Guldberg O (2012) Mushroom corals overcome live burial through pulsed inflation. Coral Reefs 31:399

Hoeksema B (1991) Control of bleaching in mushroom coral populations (Scleractinia: Fungiidae) in the Java Sea: stress tolerance and interference by life history strategy. Mar Ecol Prog Ser 75:225-237

Wooldridge SA (2014) Differential thermal bleaching susceptibilities amongst coral taxa: re-posing the role of the host. Coral Reefs 33:15-27

Electronic supplementary material The online version of this article (doi:10.1007/s00338-0161473-5) contains supplementary material, which is available to authorized users.

B. M. Lewis $(\bowtie) \cdot$ L. D. Nothdurft · L. N. Nothdurft

Earth, Environmental and Biological Science, Queensland University of Technology, Brisbane, QLD 4001, Australia

e-mail: bm.lewis@qut.edu.au 